\title{
The role of anticipation in drug addiction and reward
}

\author{
This article was published in the following Dove Press journal: \\ Neuroscience and Neuroeconomics \\ 14 December 2013 \\ Number of times this article has been viewed
}

\section{Paweł Jędras \\ Andrew Jones \\ Matt Field}

Department of Psychological Sciences, University of Liverpool, Liverpool, UK
Correspondence: Matt Field

Department of Psychological Sciences, University of Liverpool, Liverpool,

L69 7ZA, UK

Tel +44 0 I5 I 794 । I 24

Email mfield@liv.ac.uk
Abstract: Addiction is a chronically relapsing disorder, and substance users frequently relapse when they encounter opportunities to use drugs. In this paper, we review evidence regarding the psychological response to anticipation of imminent drug availability, its neural substrates, and its relationship to other phenomena implicated in addiction. Naturalistic and laboratory studies indicate that drug anticipation increases cue-provoked craving and attentional biases for drug-related cues. As predicted by existing theoretical models, these effects reflect hypervaluation of drugs that are perceived as available for consumption, which is linked to activation of the dorsolateral prefrontal cortex that, in turn, innervates subcortical regions associated with reward processing. Drug expectancy is necessary for the formation of conditioned responses to drug-related cues and it modulates the strength of conditioned responses. Furthermore, the role of impulsivity in addiction can be understood in terms of its interaction with the response to imminent drug availability. These results have a number of implications for the treatment of addiction, ranging from government policies that restrict the perceived availability of drugs to novel biological and psychological interventions that could blunt the response to signals of drug availability.

Keywords: attentional bias, availability, conditioning, cue-reactivity, expectancy, substance use disorders

\section{Introduction}

The majority of addicted individuals will relapse to drug use after a period of abstinence. ${ }^{1}$ Relapses are frequently attributed to the presence of others who are using the drug, or to being in an environment in which the drug is readily available, such as a bar. ${ }^{2-5}$ A large body of research demonstrates that the anticipation of an imminently available psychoactive drug has a potent emotional and motivational effect in addicts. In Memoirs of an Addicted Brain, the neuroscientist and recovered addict Marc Lewis describes the experience eloquently:

I sit at the dinner table, gazing down at my plate, and imagine that liquid pearl of opium dripping from that Chinese woman's skewer. And my ventral striatum says "That's what I want. That's exactly what I want, and I want it now." ${ }^{6}$

In this paper, we will discuss theoretical models that incorporate a key role for drug anticipation in the development of substance use disorders (more colloquially known as addiction). ${ }^{7}$ We will then review evidence regarding the role of drug anticipation in learning, subjective craving, cognitive processing, and the underlying neural substrates of these effects. Finally, we will discuss the clinical implications of 
this work and how it can be applied in the search for more effective treatments for substance use disorders.

\section{Theoretical background}

Smith et $\mathrm{al}^{8}$ propose that reward (including drug reward) comprises three distinct components: liking, wanting, and learning. Drugs are initially used primarily for their hedonic rewarding properties (liking). With repeated drug use, a Pavlovian conditioning process (learning) causes the rewarding properties of drugs to be paired with environmental cues that are present at the time of drug consumption, such as the sight and smell of alcoholic drinks or cigarettes. As addiction progresses, excessive wanting for the drug develops, which leads to compulsive drug use and loss of control. This wanting process is thought to reflect adaptations in dopamine function in the brain reward system (including the nucleus accumbens [NAcc] and ventral tegmental area [VTA]) as well as impaired function in subregions of the prefrontal cortex. In the addicted brain, excessive wanting can be evoked by drug-related cues, which trigger increases in dopamine activity in the reward system. This increase in dopamine activity is experienced as the expectation of imminent consumption of the drug, which is powerfully motivating. ${ }^{9}$

There is now a broad consensus regarding the core psychological changes that occur in addiction. That is, dependent individuals continue to use drugs despite negative consequences because they overestimate the hedonic rewarding value of the substance, but become relatively insensitive to other forms of reinforcement (eg, from social interactions and/or occupational achievement).$^{10}$ It has been proposed that addiction is maintained because the expectation of hedonic effects obtained from drug reward becomes more motivating over time. However, at the same time, both cognitive control and the actual hedonic effects of drugs begin to decline..$^{9,11}$ Anticipation of the hedonic effects of drugs can be triggered by information that the drug is available (eg, "Would you like a beer?") or by the detection of drug-related cues that signal the availability of the drug. ${ }^{12}$ Therefore, the theories discussed in this section propose that anticipation of drug effects evokes powerful motivational and emotional responses that may maintain drug use, despite negative consequences of drug use and the fact that the hedonic experience of drug use never quite lives up to that which was anticipated.

\section{Does drug expectancy play a role in drug conditioning?}

The theoretical models discussed in the previous section suggest that reactivity to drug-related cues occurs because those cues have been repeatedly paired with the rewarding effects of drugs, which leads to the formation of conditioned associations. Exposure to drug-related cues reliably leads to increased craving and physiological arousal in drug users. These responses have been documented in patients with alcohol, nicotine, opiate, and cocaine dependence as well as in pathological gamblers. ${ }^{13-17}$ According to conditioning accounts of cue reactivity, the drug acts as an unconditioned stimulus (US) that elicits unconditioned responses. With repeated drug use, the user learns the contingency between drug effects and cues associated with drug administration (eg, the sight and smell of a lit cigarette) such that those cues function as conditioned stimuli (CS) that are able to evoke conditioned responses (CRs). Once the CS-US contingency has been learned, the CS functions as a signal for the imminent availability of the drug, and, arguably, it is this anticipation that is responsible for the initial development of CRs such as changes in subjective state (particularly craving), physiological changes (eg, increases in heart rate), and behavioral responses (such as drug-taking behavior). ${ }^{18,19}$

Awareness of CS-US contingencies may be a crucial condition for the initial development of CRs. A considerable number of human conditioning studies demonstrate that, during the formation of conditioned associations, participants show CRs only after they can verbalize the CS-US contingency, ie, when presentation of the CS leads to the expectation that the US is imminent. ${ }^{20}$ This is also true when participants are learning associations between the opportunity to consume drugs and arbitrary stimuli. An arbitrary cue that is paired with smoking is able to evoke an increase in cigarette craving (and other conditioned responses), but only after participants have learned the predictive significance of the cue, such that its presence elicits an expectation of the opportunity to smoke. ${ }^{21}$ For example, one study ${ }^{22}$ showed that a CS that had been paired with the opportunity to smoke (CS+) led to increased cigarette craving compared to a CS that had been explicitly unpaired with the opportunity to smoke (CS-). This CR (craving) was particularly pronounced in individuals who were aware of the contingency between the CS and the US. Furthermore, the craving CR to the CS+ (versus the CS-) was completely abolished if participants were informed that smoking was unavailable. This study, and several others reviewed by Hogarth and Duka, ${ }^{21}$ reveal that drug expectancy in response to a CS that is paired with a drug use opportunity is an important determinant of other CRs in response to that cue. ${ }^{18}$ To summarize, drug-related cues are able to evoke craving and physiological arousal only when individuals are aware of the predictive significance of 
those cues, such that their presence leads to an expectation that the drug is available.

\section{Naturalistic studies of the effects of drug anticipation}

Theoretical models suggest that drug expectancy should increase craving, and results from studies discussed in the previous section demonstrate that this is an important determinant of the development of craving reactivity to drug-related cues. Two elegant studies demonstrate that drug expectancy influences the strength of craving in naturalistic settings, outside of the laboratory. Dar et $\mathrm{al}^{23}$ assessed the strength of cigarette craving in flight attendants during a twoway short flight (each leg was between 3 and 5.5 hours in duration) and a one-way long flight (between 8 and 13 hours duration). In both short and long flights, the strength of craving increased gradually and peaked as landing approached. The strength of craving appeared to be proportional to the proximity to the opportunity to smoke, rather than to the duration of nicotine deprivation; craving strength at the end of the first leg of the short flight was comparable to that at the end of the long flight (when a smoking opportunity was imminent). However, craving was much stronger at the end of the first leg of the short flight compared to the equivalent time point in the long flight, when the duration of nicotine deprivation was the same. This study demonstrates that cigarette craving increases when individuals anticipate an imminent opportunity to smoke and decreases when cigarettes are not available for a period of time. Although nicotine deprivation also influences the strength of cigarette craving, the powerful effects of smoking opportunity can be clearly seen when nicotine deprivation is controlled.

In another study, Dar et $\mathrm{al}^{24}$ investigated the effects of habitual abstinence on cigarette craving in a population of Orthodox Jewish smokers. Craving strength was generally lower during the Sabbath (when Orthodox Jews must not smoke) in comparison to both a regular workday, when they could smoke as usual, and on a different workday, when smoking was not permitted. However, craving levels did not differ between the regular workdays in which smoking was allowed versus those in which smoking was not permitted. One interpretation of these findings is that, when individuals habitually abstain from drug use for religious reasons, they may perceive the drug as "unavailable" on those days, and this results in lower craving. On the other hand, the absence of a difference in the strength of craving on working days when smoking was permitted versus days on which it was not allowed suggests that the effects of smoking opportunity on cigarette craving in naturalistic settings are moderated by other factors, such as the reason for the opportunity, or lack thereof, to smoke.

\section{Laboratory research exploring the role of drug expectancy on cue reactivity and subjective craving}

In addition to the aforementioned naturalistic studies, ${ }^{23,24}$ laboratory research reveals that the anticipation of drug availability can have a robust impact on the strength of subjective craving, particularly craving that is evoked by drug-related cues. Numerous studies demonstrated that the strength of subjective craving during drug cue exposure was significantly higher among participants who were able to use the drug soon after cue exposure versus those who were not. Some of these studies also suggested that craving was elevated when drug use was anticipated, even among participants who were not exposed to drug cues ${ }^{12,25-31}$ (see Wertz and Sayette ${ }^{32}$ for review). The majority of these studies were conducted with cigarette smokers, although one study demonstrated comparable findings in individuals with cocaine dependence. In this study, all participants received a dose of cocaine, but one group was expecting to receive cocaine whereas another group believed that there was only a 33\% chance that they would receive the drug. The most important finding was that the participants who were expecting to receive cocaine reported significantly higher levels of cocaine craving immediately before the cocaine was actually administered, compared to the participants who were uncertain if they would receive cocaine. ${ }^{33}$ Overall, these studies are consistent with the suggestion that subjective craving may involve anticipation of further drug-related reward. ${ }^{10}$

Despite this consistency, some studies have failed to replicate the finding of increased craving in response to drug cues when the drug is perceived as available. Field and Duka ${ }^{34}$ observed no effects of smoking opportunity on craving and physiological measures of smoking cue reactivity. However, those authors noted that participants who expected to be able to smoke soon still had to wait around 20 minutes before they were able to smoke, and this delay may have reduced the impact of the expectancy information. With regard to alcohol cue reactivity, Davidson et $\mathrm{al}^{35}$ and Kruse et $\mathrm{al}^{36}$ found no effect of alcohol availability on subjective craving in response to alcohol cues, although the anticipation of alcohol did lead to a reduction in negative mood in the Davidson et al ${ }^{35}$ study. One study demonstrated that craving induced by alcohol cues was stronger in participants who thought that they could not consume alcoholic drinks after cue exposure compared to 
those who expected to be able to consume alcohol ${ }^{37}$ (see also MacKillop and Lisman $^{38}$ ). The latter findings are consistent with Tiffany's ${ }^{39}$ theoretical model. This model posits that drug self-administration becomes habitual in experienced users, such that it is elicited automatically in the absence of strong cravings. However, addicts experience cravings when automatic drug self-administration behaviors are blocked because the drug is not available. Therefore, the findings from this study lend support to Tiffany's model, although it is notable that the other studies discussed in this section fail to support the predictions made by this model.

Overall, it is possible that anticipation of imminent drug availability may lead to increased craving, but exposure to drug cues alongside information that the drug cannot be consumed may lead to frustration and negative mood, which leads to increased craving via a different mechanism. A further possibility is that drug expectancy has differential effects on craving for tobacco and alcohol. We emphasize that there are so few studies on this topic that this issue, and these alternative explanations, await further study.

\section{Effects of drug expectancy on attentional bias for drug cues}

In addition to its effects on subjective craving, drug expectancy influences other aspects of cue reactivity including attentional biases for drug cues. It is known that drug users have an attentional bias for drug-related cues; drug cues are able to capture and hold their attention at the expense of other stimuli. ${ }^{18}$ It has been demonstrated that attentional biases for drug cues develop as a consequence of the same classical conditioning process that results in other aspects of cue reactivity, including changes in physiological activity and subjective craving, ${ }^{40}$ as discussed in the previous section on conditioning. Whilst the clinical relevance of attentional bias in substance use disorders is debated, ${ }^{41}$ it is generally agreed that attentional bias is modulated by dopamine activity ${ }^{42}$ and it reflects the current motivational value of the drug. ${ }^{43,44}$

Field and $\mathrm{Cox}^{18}$ proposed that, during conditioning, drug cues elicit an expectation of imminent drug availability and, as a consequence of this, the drug user preferentially shifts their attention to the cue. This theory makes the prediction that attentional bias for drug cues should be moderated by the perceived availability of the drug. Wertz and Sayette ${ }^{45}$ showed that attentional bias for smoking-related words was highest in nicotine-deprived smokers who expected to be able to smoke imminently compared to those who believed that they would not be able to smoke, or who were uncertain if they could smoke or not. These effects were replicated by
McCarthy et $\mathrm{al}^{46}$ who showed that anticipation of smoking increased attentional bias for smoking-related words and other emotionally valenced words in smokers who were deprived from nicotine, but there were no effects of smoking expectancy in smokers who were nicotine sated at the time of testing. Using a within-subjects design, Field et $\mathrm{al}^{47}$ informed social drinking (nondependent) participants about the probability that they would receive beer $(100 \%, 50 \%$, or $0 \%$ ) before each trial of an eye-tracking task. During this task, alcohol-related and neutral pictures were presented on a computer screen while participants' eye movements were recorded. Results revealed that attentional bias for alcohol cues was elevated when participants expected to be able to consume alcohol imminently, compared to when they knew that alcohol was not available. However, this sensitivity to availability information was only seen in relatively light drinkers. In heavier drinkers, attentional bias for alcohol cues was seen regardless of availability information. This finding may suggest that attentional bias can become decoupled from anticipation of reward in those who drink more heavily or more frequently (see also Hogarth et $\mathrm{al}^{48}$ for broader discussion of this issue).

In a follow-up study, Jones et $\mathrm{al}^{49}$ used a similar methodology and replicated the basic demonstration of increased attentional bias for alcohol cues when alcohol was anticipated imminently. However, unlike in the Field et a ${ }^{47}$ study, these effects were apparent in all participants regardless of whether they were a relatively heavy or light drinker. In the same study, Jones et $\mathrm{al}^{49}$ also demonstrated that anticipation of chocolate reward led to increased attentional bias for chocolate-related cues, which suggests that the effects of reward anticipation on attentional bias are not limited to drugs of abuse, but are seen with all rewarding stimuli (however, see Werthmann et al, ${ }^{50}$ discussed below). Importantly, in the Jones et $\mathrm{al}^{49}$ study there was some crossover of these effects, because anticipation of alcohol led to increased attentional bias for chocolate cues and vice versa. This demonstration that the effects of reward anticipation on attentional bias are general rather than specific to the reward that is anticipated is problematic for conditioning-based accounts of this effect. ${ }^{18}$ However, methodological issues in this study may account for these findings and suggest an alternative explanation for the results, as discussed in Jones et al. ${ }^{49}$

Finally, a recent study from Werthmann et $\mathrm{al}^{50}$ found no effect of perceived availability of chocolate on attentional biases for chocolate-related cues. However, in this study there was a fairly long interval (we estimate it at 15-20 minutes) between giving participants the availability 
information and the actual opportunity to consume chocolate. Therefore, the null effects may be attributed to the availability information losing its motivational impact because the reward was not available soon enough, as discussed in relation to the Field and Duka ${ }^{34}$ study in a previous section. The available studies suggest that the effects of anticipation of drugs (and other rewards) on attentional bias are readily detected when anticipation (expectancy) is manipulated on a within-subjects, trial-by-trial basis, which ensures that participants expect to receive the reward (or not receive it) at the exact moment that attentional bias is measured.

\section{The underlying neural circuitry of reward anticipation}

Research on patterns of brain activation during drug cue reactivity has identified an important role for drug anticipation. Wilson et $\mathrm{al}^{51}$ identified two regions of the prefrontal cortex - the orbitofrontal cortex (OFC) and the dorsolateral prefrontal cortex (DLPFC) - that were reliably activated by drug-related stimuli in current or continuing drug users, ie, those who were not receiving treatment at the time of testing. In drug users who were receiving treatment at the time of testing, the OFC and DLPFC were not activated during drug cue exposure. Wilson et al's ${ }^{51}$ explanation was that these differential patterns of brain activity during drug cue exposure can be attributed to the greater expectancy of drug use in the current drug users compared to those seeking treatment, because, presumably, the former group were able to use drugs as soon as they finished taking part in the study whereas the latter group were not. Subsequent studies have manipulated the availability of smoking on a trial-bytrial basis while smokers (who are not attempting to quit) are exposed to smoking cues, and results have supported this account; activity in the OFC and DLPFC in response to smoking cues was increased when smokers perceived an opportunity to smoke, compared to when smoking was not available. ${ }^{52-54}$ Furthermore, deactivation of the DLPFC with transcranial magnetic stimulation (TMS) eliminated the effect of smoking expectancy on subjective craving. In addition, this deactivation of the DLPFC reduced the degree of activation in the OFC that was evoked by the anticipation of smoking. ${ }^{54}$ Hayashi et al ${ }^{54}$ concluded that the function of the DLPFC in this context is to increase the subjective value of the drug in response to availability information. This value information is then transmitted to other cortical (OFC, anterior cingulate cortex) and subcortical (eg, NAcc) regions of the brain.
Other studies have confirmed the role of the DLPFC in anticipation of other types of reward. Anticipation of monetary reward directly increases activation of the DLPFC, and thereby indirectly increases activity in the NAcc and VTA, ${ }^{55}$ a similar pattern of activity to that reported in the Hayashi et $\mathrm{al}^{54}$ study on smoking availability. Other studies conducted with humans and primates have confirmed that the DLPFC is involved in intertemporal valuations, ie, the sensitivity to immediate versus delayed reinforcement. ${ }^{56-58}$ In summary, the DLPFC can be considered as one of the primary brain substrates involved in the response to drug expectancy.

\section{How does drug expectancy relate to loss of control in addiction?}

We have shown that drug expectancy has clear effects on subjective craving and attentional bias for drug cues, and we have identified the DLPFC as an important neural substrate of these effects. In this section, we show that the effects of drug expectancy are related to aspects of loss of control in addiction. Substance use disorders are characterized by elevated impulsivity. Arguably, impulsivity comprises two distinct components: temporal discounting (or cognitive impulsivity) and disinhibition (or motor impulsivity). ${ }^{59}$ Temporal discounting and disinhibition are well-established features of substance use disorders. ${ }^{60,61}$ Importantly, both components of impulsivity are related to the effects of drug expectancy on drug users.

Temporal discounting (or delay discounting) refers to the tendency to devalue rewards as a function of the delay to their receipt; most people would prefer to receive $\$ 10$ now than $\$ 11$ next month, for example. This preference for immediate gratification is greatly exaggerated in those with substance use disorders. ${ }^{60}$ Bickel and Marsch ${ }^{62}$ argued that a high level of delay discounting could result in preference shifts that ultimately increase the risk of relapse to drug use after a period of abstinence. In a treatment setting, when an abstinent drug user is asked about their intentions to remain abstinent in the long-term, they may indicate that they prefer a life of abstinence (that carries long-term benefits to their health and general well-being) instead of a life of drug use (that involves immediate gratification but is harmful in the long-term). However, this preference is (sincerely) expressed in a treatment setting in which there is no opportunity to use the drug in the near future. When the drug user leaves the treatment setting, it is only a matter of time before they encounter an opportunity to use the drug again. This time the choice is between immediate gratification versus maintaining the commitment to the longer-term goal of abstinence (which carries 
long-term but not immediate benefits). Elevated rates of delay discounting in drug users can explain why they are particularly vulnerable to such preference shifts and, therefore, likely to relapse after a period of abstinence. ${ }^{60,63,64}$ Most relevant to the current review paper, we have shown that the strong emotional and motivational response to drug availability information can explain why these preference shifts occur.

Disinhibition is defined as the inability to suppress, delay, or change a response that is no longer required or is inappropriate. This inability to control behavior can be measured in the laboratory using computer tasks, such as the stop signal $^{65}$ and go/no-go ${ }^{66}$ tasks, both of which require participants to inhibit a dominant motor response. Participants with substance use disorders tend to perform poorly on these tasks, and when participants are in a disinhibited state they are more likely to drink alcohol to excess. ${ }^{61}$ One recent study suggests that individual differences in disinhibition may moderate the strength of cue reactivity when the drug is perceived as available. Papachristou et $\mathrm{al}^{67}$ reported that, amongst social drinkers, craving for alcohol was stronger in participants who expected to receive alcohol imminently compared to those who did not. Most importantly, individual differences in disinhibition moderated these effects. Participants who were highly disinhibited and expected to receive alcohol showed a much larger increase in cue-induced alcohol craving compared to disinhibited participants who did not expect to receive alcohol. Among participants who were not highly disinhibited, expectancy of receiving alcohol had no effect on cue-induced craving. Although this result awaits replication, it suggests that disinhibition may be an important individual difference that may moderate the strength of subjective cue reactivity when drugs are perceived as available. These findings are complemented by other studies that revealed an association between impulsivity and other aspects of cue reactivity, such as attentional bias. ${ }^{68,69}$ A recent meta-analysis demonstrated a small but robust association between impulsivity and attentional bias for drug cues. ${ }^{70}$

\section{Synthesis and theoretical implications}

We propose a theoretical framework that can incorporate much of the evidence described in this review. In common with the models discussed in the first section of this paper, we suggest that, in the addicted brain, there is an imbalance between the overestimation of the rewarding value of drugs, which is combined with decreased sensitivity to alternative forms of reinforcement. The first element of this imbalance (overvaluation of drug effects) is particularly sensitive to the anticipation of imminent drug availability, which results in the development of conditioned responses to drug cues and subsequently triggers a powerful emotional and motivational response. This response can be described as an increase in the value of the drug that is experienced as elevated subjective craving in response to drug-related cues, and increased allocation of attention to those cues (attentional bias). The corresponding brain substrates are an increase in activity in the DLPFC in response to drug availability information, which innervates subcortical reward system structures such as the NAcc and VTA. ${ }^{9}$

Other features of addiction, such as increased impulsivity and poor self-control, are closely linked to this response to imminent drug availability. The increased temporal discounting that is seen in drug users can be readily explained as a result of the psychological response to imminent drug availability. Furthermore, elevated disinhibition in substance users may have a direct effect on drug-seeking behavior, ${ }^{61}$ but it may also have a more indirect effect by causing an exaggerated response to information about imminent drug availability. ${ }^{67}$ However, we must be clear that the evidence described in this review cannot provide a complete account of addiction. Other processes such as opponent processes ${ }^{71,72}$ that may ultimately lead to hedonic homeostatic dysregulation are also likely to play an important role. ${ }^{73}$

\section{Practical and clinical implications}

People with substance use disorders who wish to reduce their drug use or abstain altogether may be helped by broad policy interventions that reduce the availability of drugs or at least reduce the likelihood that they will be reminded that drugs are available for purchase or consumption. One example of the latter is recent legislation introduced in the UK that ensures that cigarettes must be hidden from view in shops. This ensures that cigarettes are still available for purchase, but people are not constantly reminded that cigarettes are available every time they walk into a shop. We suggest that bans on smoking in public places introduced in many countries around the world in recent years are likely to have the same effect. Another development is the introduction of dry bars (eg, The Brink; http://thebrinkliverpool.com/about) where people can go to socialize in the evenings but alcohol is not available for purchase. A further example is restrictions on advertising; tobacco advertising has been banned in the UK for several years, and restrictions on alcohol advertising are likely to increase in the future. We suggest that one indirect effect of such restrictions may be to reduce awareness of the availability of those drugs and thereby bring about a 
subtle but important reduction in consumption of alcohol and tobacco in the population as a whole.

Restrictions on where alcohol and tobacco can be purchased are an example of how governments can reduce the psychological impact of perceived availability of those drugs, but of course this will never be a complete solution. Illicit drugs such as heroin, cocaine, methamphetamine, and cannabis are completely illegal in most countries but they are still used by a substantial minority of the world population, despite the (il)legality of those drugs meaning that most people are rarely confronted with cues for the availability of those drugs (unless they are currently making an attempt to find somewhere to purchase them).

This leads us to a more fundamental point about drug availability, which is that psychological representations of drug availability may be more important than the physical availability of that drug. For example, alcohol consumers could probably purchase alcohol whenever they want to. However, we tentatively suggest that they probably do not perceive alcohol as available all the time for a variety of reasons (eg, they are at work and they do not drink alcohol at work). It should be emphasized that further research is required in order to investigate this suggestion. We also suggest that psychological interventions for substance use disorders should attempt to target and boost representations of (un)availability of drugs. Arguably, some forms of psychological treatment, such as cognitive behavioral therapy, already do this, for example, by encouraging drug users to form a more realistic expectation of the immediate outcomes of drug use (eg, "it will not feel as good as you expect it to"). Alternatively, drug users may be encouraged to restrict their use by thinking of drugs as unavailable at certain times or in certain contexts, and gradually increase the number of situations at which drug use is considered unavailable. ${ }^{2}$ We speculate that recovered addicts who are able to achieve long-term (or permanent) abstinence are able to do so because they reach a point at which they consider drugs to be permanently unavailable (despite their obvious physical availability). The key to understanding recovery from addiction may be to understand how this occurs, and this awaits empirical testing in future research.

The evidence discussed in this paper suggests some additional approaches to the treatment of substance use disorders that could be explored. Firstly, cue exposure therapy (CET) has arguably proved to be an ineffective treatment for addiction because it does not incorporate a role for perceived availability. ${ }^{74}$ In this therapy, substance users are exposed to drug-related cues in treatment settings until their responses to those cues (eg, craving and physiological arousal) are extinguished. The hope is that this will lead to a blunting of cue reactivity outside of the treatment context and relapse will be less likely to occur. However, metaanalysis indicates that CET does not reduce relapse rates. ${ }^{74}$ This may be because CET sessions always take place in treatment settings where drugs are not available, so the drug expectancy response is never evoked and therefore cannot be extinguished. One solution may be to try to selectively extinguish the drug expectancy response, perhaps by asking substance users to imagine that they will soon be consuming the drug, and allowing this particular response to extinguish. Secondly, if activity in the DLPFC in response to signals of drug availability could somehow be blunted, this may prevent the emotional and motivational response to drug expectancy from gathering strength and (in some cases) leading to relapse after a period of abstinence. Some methods for achieving this may include repeated sessions of transcranial magnetic stimulation applied to the area ${ }^{75,76}$ or some form of cognitive training that could lead to a blunting of activity in the DLPFC in response to availability information. ${ }^{77}$ Finally, existing psychological therapies, such as cognitive behavioral therapy, might be improved by incorporating additional elements that explicitly target the emotional response to imminent drug availability and focus on ways of preparing for and coping with the response when it occurs.

\section{Limitations and directions for future research}

Much of the experimental work on perceived substance availability and subjective craving has been conducted with tobacco smokers. However, when similar studies have been attempted with alcohol consumers, results have not always been consistent. There is, therefore, a risk that we may use this evidence to develop theoretical models of substance use disorders when those models may be more relevant for some substance use disorders than others. Further research is required to establish whether the findings reported here can be generalized to substance use disorders other than addiction to tobacco.

Laboratory research has provided us with a good understanding of the psychological response to instructed drug availability and the brain mechanisms that underlie this response. However, it is unclear how this research translates to our understanding of the effects of perceived drug use opportunity in naturalistic settings outside of the laboratory. An important gap 
in our knowledge here is how substance users represent drug availability and what they can do to boost representations of drugs as unavailable. This is likely to lead to important insights into novel treatments for substance use disorders.

\section{Conclusion}

The psychological response to perceived drug availability is a very important piece of the addiction puzzle. Subjective craving and attentional biases for drug-related cues are elevated when substance users perceive drugs as available, and these effects are likely to reflect an increase in the subjective value of drugs that are anticipated imminently. The response to drug availability plays an important role in the development and maintenance of reactivity to drug-related cues, and individual differences in impulsivity may influence drug-seeking behavior precisely because they interact with, or even directly determine, the response to perceived drug availability. Innovations in treatment for substance use disorders are likely to follow from an improved understanding of why drug expectancy has such powerful and wide-ranging effects, and an understanding of what can be done to mitigate these effects.

\section{Disclosure}

The authors report no conflicts of interest in this work.

\section{References}

1. Hunt WA, Barnett LW, Branch LG. Relapse rates in addiction programs. J Clin Psychol. 1971;27(4):455-456.

2. Beck AT, Wright FD, Newman CF, Liese BS. Cognitive Therapy of Substance Abuse. New York: The Guilford Press; 1993.

3. Hawkins J, Hollingworth W, Campbell R. Long-term smoking relapse: a study using the british household panel survey. Nicotine Tob Res. 2010;12(12):1228-1235.

4. Marlatt GA. Taxonomy of high-risk situations for alcohol relapse: evolution and development of a cognitive-behavioral model. Addiction. 1996;91 Suppl:S37-S49.

5. O'Connell KA, Shiffman S, Decarlo LT. Does extinction of responses to cigarette cues occur during smoking cessation? Addiction. 2011; 106(2):410-417.

6. Lewis M. Memoirs of an Addicted Brain: A Neuroscientist Examines his Former Life on Drugs. 1st ed. New York: PublicAffairs; 2011.

7. American Psychiatric Association. Diagnostic and Statistical Manual of Mental Disorders. 5th ed. Arlington: American Psychiatric Publishing; 2013.

8. Smith KS, Berridge KC, Aldridge JW. Disentangling pleasure from incentive salience and learning signals in brain reward circuitry. Proc Natl Acad Sci U S A. 2011;108(27):E255-E264.

9. Volkow ND, Wang GJ, Fowler JS, Tomasi D, Telang F. Addiction: beyond dopamine reward circuitry. Proc Natl Acad Sci U S A. 2011;108(37):15037-15042.

10. Goldstein RZ, Volkow ND. Drug addiction and its underlying neurobiological basis: neuroimaging evidence for the involvement of the frontal cortex. Am J Psychiatry. 2002;159(10):1642-1652.

11. Goldstein RZ, Volkow ND. Dysfunction of the prefrontal cortex in addiction: neuroimaging findings and clinical implications. Nat Rev Neurosci. 2011;12(11):652-669.
12. Thewissen R, van den Hout M, Havermans RC, Jansen A. Contextdependency of cue-elicited urge to smoke. Addiction. 2005;100(3): 387-396.

13. Niaura RS, Rohsenow DJ, Binkoff JA, Monti PM, Pedraza M, Abrams DB. Relevance of cue reactivity to understanding alcohol and smoking relapse. J Abnorm Psychol. 1988;97(2):133-152.

14. Childress AR, Hole AV, Ehrman RN, Robbins SJ, McLellan AT, O'Brien CP. Cue reactivity and cue reactivity interventions in drug dependence. NIDA Res Monogr. 1993;137:73-95.

15. Carter BL, Tiffany ST. Meta-analysis of cue-reactivity in addiction research. Addiction. 1999;94(3):327-340.

16. Drummond DC. What does cue-reactivity have to offer clinical research? Addiction. 2000;95 Suppl 2:S129-S144.

17. Tsurumi K, Takahashi H. [Gambling brain]. Brain Nerve. 2013;65(1):77-83. Japanese.

18. Field M, Cox WM. Attentional bias in addictive behaviors: a review of its development, causes, and consequences. Drug Alcohol Depend. 2008;97(1-2):1-20.

19. Hogarth L, Dickinson A, Hutton SB, Bamborough H, Duka T. Contingency knowledge is necessary for learned motivated behaviour in humans: relevance for addictive behaviour. Addiction. 2006;101(8): $1153-1166$.

20. Lovibond PF, Shanks DR. The role of awareness in Pavlovian conditioning: Empirical evidence and theoretical implications. $J$ Exp Psychol Anim Behav Process. 2002;28(1):3-26.

21. Hogarth L, Duka T. Human nicotine conditioning requires explicit contingency knowledge: is addictive behaviour cognitively mediated? Psychopharmacology (Berl). 2006;184(3-4):553-566.

22. Field M, Duka T. Smoking expectancy mediates the conditioned responses to arbitrary smoking cues. Behav Pharmacol. 2001;12(3):183-194.

23. Dar R, Rosen-Korakin N, Shapira O, Gottlieb Y, Frenk H. The craving to smoke in flight attendants: relations with smoking deprivation, anticipation of smoking, and actual smoking. J Abnorm Psychol. 2010;119(1):248-253.

24. Dar R, Stronguin F, Marouani R, Krupsky M, Frenk H. Craving to smoke in orthodox Jewish smokers who abstain on the Sabbath: a comparison to a baseline and a forced abstinence workday. Psychopharmacology (Berl). 2005;183(3):294-299.

25. Juliano LM, Brandon TH. Reactivity to instructed smoking availability and environmental cues: evidence with urge and reaction time. Exp Clin Psychopharmacol. 1998;6(1):45-53.

26. Dols M, Willems B, van den Hout M, Bittoun R. Smokers can learn to influence their urge to smoke. Addict Behav. 2000;25(1):103-108.

27. Carter BL, Tiffany ST. The cue-availability paradigm: the effects of cigarette availability on cue reactivity in smokers. Exp Clin Psychopharmacol. 2001;9(2):183-190.

28. Dols M, van den Hout M, Kindt M, Willems B. The urge to smoke depends on the expectation of smoking. Addiction. 2002;97(1):87-93.

29. Thewissen R, van der Meijden VA, Havermans RC, van den Hout M, Jansen A. From the office to the pub: the role of smoking-relevant contexts and cue-elicited urge to smoke. Eur Addict Res. 2008;14(4):198-205.

30. Thewissen R, Snijders SJ, Havermans RC, van den Hout M, Jansen A. Renewal of cue-elicited urge to smoke: implications for cue exposure treatment. Beh Res Ther. 2006;44(10):1441-1449.

31. Droungas A, Ehrman RN, Childress AR, O'Brien CP. Effect of smoking cues and cigarette availability on craving and smoking behavior. Addict Behav. 1995;20(5):657-673.

32. Wertz JM, Sayette MA. A review of the effects of perceived drug use opportunity of self-reported urge. Exp Clin Psychopharmacol. 2001;9(1):3-13.

33. Yamamoto RT, Karlsgodt KH, Rott D, Lukas SE, Elman I. Effects of perceived cocaine availability on subjective and objective responses to the drug. Subst Abuse Treat Prev Policy. 2007;2:30.

34. Field M, Duka T. Cue reactivity in smokers: the effects of perceived cigarette availability and gender. Pharmacol Biochem Behav. 2004;78(3):647-652. 
35. Davidson D, Tiffany ST, Johnston W, Flury L, Li TK. Using the cueavailability paradigm to assess cue reactivity. Alcohol Clin Exp Res. 2003;27(8):1251-1256.

36. Kruse MI, Radnovich AJ, Kalapatapu RK, Mehdiyoun N, Chambers RA, Davidson D. Effects of alcohol availability, access to alcohol, and naltrexone on self-reported craving and patterns of drinking in response to an alcohol-cue availability procedure. J Stud Alcohol Drugs. 2012;73(2):205-215.

37. MacKillop J, Lisman SA. Reactivity to alcohol cues: isolating the role of perceived availability. Exp Clin Psychopharmacol. 2005;13(3): 229-237.

38. Mackillop J, Lisman SA. Examining the effect of perceived availability on craving for alcohol: A quasi-experimental approach. Addict Res Theory. 2007;15(3):231-245.

39. Tiffany ST. A cognitive model of drug urges and drug-use behavior: role of automatic and nonautomatic processes. Psychol Rev. 1990;97(2):147-168.

40. Hogarth L, Dickinson A, Hutton SB, Elbers N, Duka T. Drug expectancy is necessary for stimulus control of human attention, instrumental drug-seeking behaviour and subjective pleasure. Psychopharmacology (Berl). 2006;185(4):495-504.

41. Field M, Marhe R, Franken IH. The clinical relevance of attentional bias in substance use disorders. CNS Spectr. Epub May 13, 2013.

42. Luijten M, Field M, Franken IH. Pharmacological interventions to modulate attentional bias in addiction. CNS Spectr. Epub August 1, 2013.

43. Field M, Munafo MR, Franken IH. A meta-analytic investigation of the relationship between attentional bias and subjective craving in substance abuse. Psychol Bull. 2009;135(4):589-607.

44. Rose AK, Brown K, Field M, Hogarth L. The contributions of valuebased decision-making and attentional bias to alcohol-seeking following devaluation. Addiction. 2013;108(7):1241-1249.

45. Wertz JM, Sayette MA. Effects of smoking opportunity on attentional bias in smokers. Psychol Addict Behav. 2001;15(3):268-271.

46. McCarthy DE, Gloria R, Curtin JJ. Attention bias in nicotine withdrawal and under stress. Psychol Addict Behav. 2009;23(1):77-90.

47. Field M, Hogarth L, Bleasdale D, Wright P, Fernie G, Christiansen P. Alcohol expectancy moderates attentional bias for alcohol cues in light drinkers. Addiction. 2011;106(6):1097-1103.

48. Hogarth L, Balleine BW, Corbit LH, Killcross S. Associative learning mechanisms underpinning the transition from recreational drug use to addiction. Ann N Y Acad Sci. 2013;1282:12-24.

49. Jones A, Hogarth L, Christiansen P, Rose AK, Martinovic J, Field M. Reward expectancy promotes generalized increases in attentional bias for rewarding stimuli. $Q J$ Exp Psychol (Hove). 2012;65(12):2333-2342.

50. Werthmann J, Roefs A, Nederkoorn C, Jansen A. Desire lies in the eyes: Attention bias for chocolate is related to craving and self-endorsed eating permission. Appetite. 2013;70:81-89.

51. Wilson SJ, Sayette MA, Fiez JA. Prefrontal responses to drug cues: a neurocognitive analysis. Nat Neurosci. 2004;7(3):211-214.

52. Wilson SJ, Sayette MA, Delgado MR, Fiez JA. Instructed smoking expectancy modulates cue-elicited neural activity: a preliminary study. Nicotine Tob Res. 2005;7(4):637-645.

53. McBride D, Barrett SP, Kelly JT, Aw A, Dagher A. Effects of expectancy and abstinence on the neural response to smoking cues in cigarette smokers: an fMRI study. Neuropsychopharmacology. 2006;31(12):2728-2738.

54. Hayashi T, Ko JH, Strafella AP, Dagher A. Dorsolateral prefrontal and orbitofrontal cortex interactions during self-control of cigarette craving. Proc Natl Acad Sci U S A. 2013;110(11):4422-4427.

55. Ballard IC, Murty VP, Carter RM, MacInnes JJ, Huettel SA, Adcock RA. Dorsolateral prefrontal cortex drives mesolimbic dopaminergic regions to initiate motivated behavior. J Neurosci. 2011;31(28):10340-10346.

56. McClure SM, Ericson KM, Laibson DI, Loewenstein G, Cohen JD. Time discounting for primary rewards. J Neurosci. 2007;27(21): 5796-5804.
57. Kim S, Hwang J, Lee D. Prefrontal coding of temporally discounted values during intertemporal choice. Neuron. 2008;59(1):161-172.

58. Essex BG, Clinton SA, Wonderley LR, Zald DH. The impact of the posterior parietal and dorsolateral prefrontal cortices on the optimization of long-term versus immediate value. J Neurosci. 2012;32(44):15403-15413.

59. Olmstead MC. Animal models of drug addiction: Where do we go from here? Q J Exp Psychol (Hove). 2006;59(4):625-653.

60. MacKillop J, Amlung MT, Few LR, Ray LA, Sweet LH, Munafò MR Delayed reward discounting and addictive behavior: a meta-analysis. Psychopharmacology (Berl). 2011;216(3):305-321.

61. Jones A, Christiansen P, Nederkoorn C, Houben K, Field M. Fluctuating disinhibition: Implications for the understanding and treatment of alcohol and other substance use disorders. Front Psychiatry. 2013;4:140.

62. Bickel WK, Marsch LA. Toward a behavioral economic understanding of drug dependence: delay discounting processes. Addiction. 2001;96(1):73-86.

63. Washio Y, Higgins ST, Heil SH, et al. Delay discounting is associated with treatment response among cocaine-dependent outpatients. Exp Clin Psychopharmacol. 2011;19(3):243-248.

64. Sheffer C, Mackillop J, McGeary J, et al. Delay discounting, locus of control, and cognitive impulsiveness independently predict tobacco dependence treatment outcomes in a highly dependent, lower socioeconomic group of smokers. Am J Addict. 2012;21(3):221-232.

65. Logan GD, Cowan WB, Davis KA. On the ability to inhibit simple and choice reaction time responses: a model and a method. $J$ Exp Psychol Hum Percept Perform. 1984;10(2):276-291.

66. Newman JP, Kosson DS. Passive avoidance learning in psychopathic and nonpsychopathic offenders. J Abnorm Psychol. 1986;95(3): 252-260.

67. Papachristou H, Nederkoorn C, Corstjens J, Jansen A. The role of impulsivity and perceived availability on cue-elicited craving for alcohol in social drinkers. Psychopharmacology (Berl). 2012;224(1): 145-153.

68. Field M, Christiansen P, Cole J, Goudie A. Delay discounting and the alcohol Stroop in heavy drinking adolescents. Addiction. 2007;102(4):579-586.

69. Jones A, Rose AK, Cole J, Field M. Effects of alcohol cues on craving and ad libitum alcohol consumption in social drinkers: the role of disinhibition. J Exp Psychopathol. 2013;4(3):239-249.

70. Coskunpinar A, Cyders MA. Impulsivity and substance-related attentional bias: A meta-analytic review. Drug Alcohol Depend. 2013;133(1):1-14.

71. Solomon RL, Corbit JD. An opponent-process theory of motivation. II. Cigarette addiction. J Abnorm Psychol. 1973;81(2):158-171.

72. Solomon RL, Corbit JD. An opponent-process theory of motivation. I. Temporal dynamics of affect. Psychol Rev. 1974;81(2):119-145.

73. Koob GF. Hedonic homeostatic dysregulation as a driver of drug-seeking behavior. Drug Discov Today Dis Models. 2008;5(4): 207-215.

74. Conklin CA, Tiffany ST. Applying extinction research and theory to cue-exposure addiction treatments. Addiction. 2002;97(2): $155-167$.

75. Amiaz R, Levy D, Vainiger D, Grunhaus L, Zangen A. Repeated high-frequency transcranial magnetic stimulation over the dorsolateral prefrontal cortex reduces cigarette craving and consumption. Addiction. 2009;104(4):653-660.

76. Camus M, Halelamien N, Plassmann H, et al. Repetitive transcranial magnetic stimulation over the right dorsolateral prefrontal cortex decreases valuations during food choices. Eur J Neurosci. 2009;30(10):1980-1988.

77. Potenza MN, Sofuoglu M, Carroll KM, Rounsaville BJ. Neuroscience of behavioral and pharmacological treatments for addictions. Neuron. 2011;69(4):695-712. 


\section{Publish your work in this journal}

Neuroscience and Neuroeconomics is an international, peer-reviewed, open access journal focusing on the identification of brain structures and measurement of neural activity related to behavior, behavioral predictions, and decision making in health and disease. The manuscript management system is completely online and includes a very quick and

Submit your manuscript here: http://www.dovepress.com/neuroscience-and-neuroeconomics-journal fair peer-review system. Visit http://www.dovepress.com/testimonials. php to read real quotes from published authors. 